\title{
ANTIOXIDANT ACTIVITY OF CONJUGATED LINOLEIC ACID
}

\author{
LALITHADEVI B ${ }^{1}$, MUTHIAH NS ${ }^{2}$, SATYA NARAYANA MURTY K ${ }^{3}$
}

${ }^{1}$ Ph.D. Research Scholar, Bharath University, Chennai, Tamil Nadu, India. ${ }^{2}$ Department of Pharmacology, Sri Balaji Medical College, Chennai, Tamil Nadu, India. ${ }^{3}$ Department of Pharmacology, GSL Medical College, Rajamahendravaram - 533296, Andhra Pradesh, India. Email: lalithadevid@gmail.com

Received: 05 June 2018, Revised and Accepted: 03 July 2018

ABSTRACT

Objective: The objective of the present study is to evaluate the antioxidant effect of conjugated linoleic acid (CLA). CLA is a collective term for a group of positional and geometric isomers of linoleic acid with conjugated double bond system. CLA is found in milk products and ruminant meat. CLA has been proved to be having many health benefits, one of them one being antioxidant effect.

Methods: Various methods are used to find out the antioxidant effect of CLA. They are 1,1- diphenyl-2-picrylhydrazyl free radical scavenging assay, hydroxy radical scavenging assay, nitrous oxide radical scavenging assay, reducing power method, and phosphomolybdenum antioxidant assay. All these methods were done to test the antioxidant activity of CLA.

Results: Standards error of mean calculated for all the tests. Statistical analysis done using one-way analysis of variance between the groups and SPSS software version 20 is used. $\mathrm{p}<0.05$ is considered statistically significant. All the tests are statistically significant.

Conclusion: As p values for all the tests came significant, it was concluded that CLA has got antioxidant property. CLA could protect membranes composed of 1-palmitoyl 2-linoleoyl phosphatidylcholine from oxidative modification under conditions of metal ion-dependent or -independent oxidative stress. Finally, it was concluded that CLA has got potential health benefits such as weight reduction, antiaging, and antioxidative properties.

Keywords: Isomers of linoleic acid, Antioxidant effect, Health benefits, Analysis of variance test, 1-Palmitoyl 2-linoleoyl phosphatidylcholine.

(c) 2018 The Authors. Published by Innovare Academic Sciences Pvt Ltd. This is an open access article under the CC BY license (http://creativecommons. org/licenses/by/4. 0/) DOI: http://dx.doi.org/10.22159/ajpcr.2018.v11i11.27700

\section{INTRODUCTION}

Conjugated linoleic acid (CLA) acid is a group of positional and geometric isomers of conjugated dienoic derivatives of linoleic acid. The major dietary source of CLA for humans is ruminant meats such as beef, lamb, and dairy products including milk and cheese. The major isomer of CLA in natural foods is cis-9 trans-11 (c9t11). In the past, many in vitro studies have proved that CLA possesses antioxidative properties [1].

The rationale of the study is to find out whether CLA can be given in place of the conventional drugs, thereby reducing the adverse effects, and at the same time, it can be used as an antioxidant with potential health benefits. The novelty of the study is that till now the studies are very few in humans and once the antioxidative properties are proved then the drug is going to be very much beneficial for use in humans.

The human body has got many defense mechanisms which are enzymatic and non-enzymatic defense mechanisms which counteract the harmful effects of free radicals and other oxidants. Free radicals are responsible for causing a large number of diseases including cancer [2]. Other diseases caused by free radicals are cardiovascular disease [3], neural disorders [4], Alzheimer's disease, mild cognitive impairment, Parkinson's disease [5], ulcerative colitis, and atherosclerosis [6]. Protection against free radicals can be enhanced by ample intake of dietary antioxidants. Through substantial evidence, it was proved that foods containing antioxidants, especially the antioxidant nutrients may be of major importance in disease prevention. According to scientists, a combination of antioxidants, rather than single entities, may be effective over the long term. Antioxidants may be of great benefit in improving the quality of life by preventing or postponing the onset of degenerative disorders. Furthermore, they have a potential for substantial savings in the cost of health-care delivery.
Several studies have proved the antioxidant activity of CLA [7-10]. Various methods are used to investigate the antioxidant property of samples, for example, diets, plant extracts, commercial antioxidants, etc. While describing the two isomers of CLA, they are c9t11 and trans-10 cis-12 isomers ( $\mathrm{t} 10 \mathrm{c} 12)$, these two isomers exist in natural as well as synthetic forms. In this study, in vitro antioxidant activity of CLA has been studied.

\section{In vitro methods for antioxidant activity}

Antioxidant activity should not be concluded based on a single antioxidant test model. In practice, several in vitro test procedures are carried out for evaluating antioxidant activities with the samples of interest. Antioxidant test models also vary in different respects. Therefore, it is difficult to compare fully one method to the other one. The comparison against different methods was conducted by Badarinath et al. [11]. In general, in vitro antioxidant tests using free radical traps are relatively straightforward to perform. Among free radical scavenging methods, 1,1-diphenyl-2-picrylhydrazyl (DPPH) method is furthermore rapid, simple, and inexpensive in comparison to other test models.

\section{MATERIALS AND METHODS}

The test drug CLA was tested for its antioxidant activity in the following methods.

\section{Reducing power method}

This method is based on the principle of increase in the absorbance of the reaction mixtures. Increase in the absorbance indicates the increase in the antioxidant activity and the reducing power of the samples [12].

\section{Principle}

Reduced power is based on the principle that substances which have reduction potential, react with potassium ferricyanide $\left(\mathrm{Fe}^{3+}\right)$ to form 
potassium ferrocyanide which then reacts with ferric chloride to form ferriferous complex that has an absorption maximum at 700 nanometers $(\mathrm{nm})$.

\section{Preparation of standard concentration}

The standard gallic acid 50 micrograms $(\mu \mathrm{g})$ per $\mathrm{ml}$ stock solution in methanol was prepared, and further dilutions, $1 \mu \mathrm{g} / \mathrm{ml}, 2.5 \mu \mathrm{g} / \mathrm{ml}$, and $5 \mu \mathrm{g} / \mathrm{ml}$ in methanol were prepared for the study.

\section{Preparation of the test sample}

The CLA $1 \mathrm{mg} / \mathrm{ml}$ prepared in distilled water, and further dilutions, 5, 10, $20,40,80,100,125$, and $150 \mu \mathrm{g} / \mathrm{ml}$ prepared for the study. Phosphate buffer was prepared and maintained at $\mathrm{pH} 6.6$ with hydrochloric acid.

\section{Procedure}

Fe reduction is often used as an indicator of electron donating activity, which is an important mechanism of phenolic antioxidant action. Different concentrations of CLA which were previously prepared in $1 \mathrm{ml}$ of distilled water were mixed with phosphate buffer and $\mathrm{Fe}^{3+}$. The mixture was incubated at $50^{\circ} \mathrm{C}$ for $20 \mathrm{~min}$. A portion $(2.5 \mathrm{ml})$ of trichloracetic acid $(10 \%)$ was added to the mixture, which was then centrifuged at 3000 revolutions per minute (rpm) for $10 \mathrm{~min}$. The upper layer of solution $(2.5 \mathrm{ml})$ was mixed with distilled water $(2.5 \mathrm{ml})$ and $\mathrm{FeCl} 3(0.5 \mathrm{ml}, 0.1 \%)$, and the absorbance was measured at $700 \mathrm{~nm}$. Ascorbic acid was used as the reference material. All the tests performed in triplicate and the results averaged. Increased absorbance of the reaction mixture indicates increase in reducing power and hence antioxidant activity.

\section{Phosphomolybdenum antioxidant assay}

The total antioxidant capacity assay is a spectroscopic method for the quantitative determination of antioxidant capacity, through the formation of a green phosphate Mo (V) complex at acidic $\mathrm{pH}$. The assay is based on the reduction of Mo (VI) - Mo (V) by the sample and the subsequent formation of the green phosphate. Total antioxidant capacity can be calculated by the method described by Prieto et al. [13].

The standard, Gallic acid $50 \mu \mathrm{g} / \mathrm{ml}$ stock solution in methanol was prepared and further dilutions $1 \mu \mathrm{g} / \mathrm{ml}, 2.5 \mu \mathrm{g} / \mathrm{ml}, 5 \mu \mathrm{g} / \mathrm{ml}$ in methanol were prepared for the study. The CLA was also prepared in dilutions of $5,10,20,40,80,100,125$ and $150 \mu \mathrm{g} / \mathrm{ml}$ for the study.

\section{Procedure}

$0.3 \mathrm{ml}$ of sample $(\mathrm{mg} / \mathrm{ml})$ was combined with $3 \mathrm{ml}$ of reagent solution ( $0.6 \mathrm{M}$ sulfuric acid, $28 \mathrm{mM}$ sodium phosphate, and $4 \mathrm{mM}$ ammonium molybdate). The tubes containing the reaction solution were incubated at $95^{\circ} \mathrm{C}$ for $90 \mathrm{~min}$. After cooling the sample to room temperature, the absorbance of the aqueous solution is measured at $695 \mathrm{~nm}$ against blank in UV spectrophotometer. A typical blank solution contained $1 \mathrm{ml}$ of reagent solution and the appropriate volume of the same solvent used for the sample, and it is incubated under same conditions as rest of the sample. Ultimately, green phosphate is formed indicating antioxidant activity of CLA.

\section{DPPH radical scavenging activity \\ Principle}

The scavenging reaction between DPPH and antioxidant $(\mathrm{H}-\mathrm{A})$ can be written as:

$(\mathrm{DPPH})+(\mathrm{H}-\mathrm{A})=\mathrm{DPPH}-\mathrm{H}+\mathrm{H}$

Purple yellow

Antioxidants react with DPPH which is a stable radical and is reduced to the DPPH-H, and as consequence, the absorbance decreased from DPPH radical to the DOOH-H form. The degree of discoloration indicated the scavenging potential of the antioxidant compounds or extracts in terms of hydrogen donating ability.
The standard gallic acid standard solution was prepared in different concentrations for the study.

\section{Preparation of DPPH solution}

$0.002 \mathrm{~g}$ of DPPH was weighed on electronic balance and dissolved in methanol; the volume is made to $100 \mathrm{ml}$ using methanol to give $0.002 \%$ DPPH solution.

The test solution CLA $1 \mathrm{mg} / \mathrm{ml}$ was prepared in distilled water and further dilutions were prepared from $10,20,40,80,100,120$, and $150 \mu \mathrm{g} / \mathrm{ml}$ of the solution for the study.

\section{Procedure of the DPPH scavenging activity}

The molecule DPPH is characterized as a stable free radical by virtue of the delocalization of the spare electron over the molecule as a whole so that the molecule does not dimerize like many other free radicals. The delocalization of the electron also gives rise to the deep violet color, characterized by an absorption band in ethanol solution centered at about $517 \mathrm{~nm}$. When a solution of DPPH is mixed with that of a substrate that can donate a hydrogen atom, then this gives rise to the reduced form with the loss of this violet color.

To evaluate the antioxidant potential through free radical scavenging by the test samples, the change in optical density of DPPH radicals is monitored. According to the method described by Manzocco et al., 1998 [14], the DPPH scavenging activity is monitored in the following manner.

$0.1 \mathrm{mM}$ solution of DPPH in methanol was prepared and $1.0 \mathrm{ml}$ of this solution was added to $3.0 \mathrm{ml}$ of extract solutions in methanol at different concentrations $(5,10,20,40,80,100,125$, and $150 \mu \mathrm{g} / \mathrm{ml}) .30 \mathrm{~min}$ later, the absorbance was measured at $517 \mathrm{~nm}$. A blank was prepared without adding extract. Ascorbic acid at various concentrations (1, 2.5, and $5 \mu \mathrm{g} / \mathrm{ml}$ ) was used as a standard. The experiment was repeated triplicate. The lower the absorbance of the reaction mixture, higher is the free radical scavenging activity. The capacity to scavenge the DPPH radical was calculated using the following equation.

DPPH scavenged $(\%)=\left\{\left(\mathrm{A}_{0}-\mathrm{A}_{1}\right) / \mathrm{A}_{0}\right\} \times 100$

Where, $\mathrm{A}_{0}=$ Absorbance of the control reaction (containing all reagents except the sample extract)

And $\mathrm{A}_{1}=$ Absorbance of the sample extract.

Ascorbic acid was used as positive control

\section{Hydroxyl radical scavenging activity}

Hydroxyl radical is one of the potent reactive oxygen species in the biological system that reacts with polyunsaturated fatty acid moieties of cell membrane phospholipids and causes damage to cell. The scavenging ability of hydroxyl radical is measured by the method of Kunchandy and Rao [15] with some modifications.

\section{Preparation of the standard concentration}

The standard gallic acid $50 \mu \mathrm{g} / \mathrm{ml}$ stock solution in methanol was prepared and further dilutions $1,2.5$, and $5 \mu \mathrm{g} / \mathrm{ml}$ were prepared for the study.

Preparation of the sample: The CLA $1 \mathrm{mg} / \mathrm{ml}$ prepared in distilled water and further dilutions of $5,10,20,40,80,125$, and $150 \mu \mathrm{g} / \mathrm{ml}$ were prepared for the study.

Individual samples $1 \mathrm{ml}$ at different concentrations $(5,10,20,40,80$, 100,125 , and $150 \mu \mathrm{g} / \mathrm{ml}$ ) were added to the reagent containing $1 \mathrm{~mL}$ $1.5 \mathrm{mM} \mathrm{FeSo} 4,0.7 \mathrm{ml} 6 \mathrm{mM} \mathrm{H} 2 \mathrm{O} 2$, and $0.3 \mathrm{ml} 20 \mathrm{mM}$ sodium salicylate. After incubation for $1 \mathrm{~h}$ at $37^{\circ} \mathrm{C}$, absorbance of the reaction mixture was read at $532 \mathrm{~nm}$. 
Table 1: Effect of CLA on hydroxy radical scavenging assay

\begin{tabular}{lll}
\hline Tested material & Concentration $(\mu \mathbf{g} / \mathbf{m l})$ & \% inhibition \\
\hline CLA & 5 & $43.15 \pm 0.002$ \\
& 10 & $49.32 \pm 0.005$ \\
& 20 & $58.90 \pm 0.001$ \\
& 40 & $63.12 \pm 0.001$ \\
& 80 & $65.24 \pm 0.005$ \\
& 100 & $69.27 \pm 0.001$ \\
Gallic acid & 125 & $76.11 \pm 0.003$ \\
& 150 & $83.56 \pm 0.007$ \\
& 1 & $55.46 \pm 0.11$ \\
& 2.5 & $65.32 \pm 0.15$ \\
& 5 & $70.98 \pm 0.07$ \\
\hline
\end{tabular}

Values are expressed as mean \pm SD. $n=3$. CLA: Conjugated linoleic acid,

SD: Standard deviation

Table 2: Effects of CLA on DPPH radical scavenging assay

\begin{tabular}{lll}
\hline Tested material & Concentration & \% inhibition \\
\hline CLA & 5 & $45.38 \pm 0.006$ \\
& 10 & $57.91 \pm 0.003$ \\
& 20 & $59.47 \pm 0.006$ \\
40 & $63.86 \pm 0.008$ \\
80 & $72.53 \pm 0.007$ \\
100 & $79.87 \pm 0.001$ \\
& 125 & $82.32 \pm 0.005$ \\
Gallic acid & 150 & $84.55 \pm 0.006$ \\
& 1 & $81.83 \pm 0.001$ \\
& 2.5 & $88.75 \pm 0.002$ \\
& 5 & $91.71 \pm 0.001$ \\
\hline
\end{tabular}

Values are expressed as mean \pm SD. $n=3$. CLA: Conjugated linoleic acid,

SD: Standard deviation, DPPH: 1,1-diphenyl-2-picrylhydrazyl

Table 3: Effects of CLA on nitric oxide radical scavenging assay

\begin{tabular}{lll}
\hline Tested material & Concentration & \% inhibition \\
\hline CLA & 5 & $44.71 \pm 0.003$ \\
& 10 & $55.68 \pm 0.004$ \\
& 20 & $64.62 \pm 0.0016$ \\
40 & $65.38 \pm 0.003$ \\
& 80 & $76.91 \pm 0.008$ \\
& 100 & $78.14 \pm 0.001$ \\
& 125 & $81.93 \pm 0.004$ \\
Gallic acid & 150 & $83.86 \pm 0.007$ \\
& 1 & $54.76 \pm 0.11$ \\
& 2.5 & $65.32 \pm 0.15$ \\
& 5 & $70.54 \pm 0.07$ \\
\hline
\end{tabular}

Values are expressed as mean \pm SD. CLA: Conjugated linoleic acid, SD: Standard deviation

The scavenging ability of hydroxyl radicals was calculated using the following equation:

Scavenging ability of hydroxyl radicals $(\%)=\left\{\left(A_{0}-A_{1}\right) / A_{0}\right\} \times 100$

Where,

$A_{0}=$ Absorbance of the control reaction (containing all reagents except the sample extract)

and $\mathrm{A}_{1}=$ Absorbance of the sample extract.

Ascorbic acid was used as positive control.

Nitric acid radical scavenging assay

Nitric oxide is generated in biological tissues by specific nitric oxide synthases, which metabolizes arginine to citrulline with the formation NO, through a five-electron oxidative reaction $[16,17]$. The compound sodium
Table 4: Effects of CLA on phosphomolybdenum assay

\begin{tabular}{lll}
\hline CLA & 5 & $0.041 \pm 0.0011$ \\
& 10 & $0.093 \pm 0.0014$ \\
20 & $0.138 \pm 0.0008$ \\
40 & $0.194 \pm 0.0011$ \\
80 & $0.254 \pm 0.0005$ \\
100 & $0.286 \pm 0.0011$ \\
& 125 & $0.371 \pm 0.0011$ \\
Gallic acid & 150 & $0.490 \pm 0.0013$ \\
& 1 & $0.093 \pm 0.00221$ \\
& 2.5 & $0.194 \pm 0.00123$ \\
& 5 & $0.310 \pm 0.00011$ \\
\hline
\end{tabular}

Values are expressed as mean \pm SD. $n=3$. CLA: Conjugated linoleic acid,

SD: Standard deviation

Table 5: Effects of CLA on reducing power method

\begin{tabular}{lll}
\hline Tested material & Concentration & \% inhibition \\
\hline CLA & 5 & $0.061 \pm 0.00513$ \\
& 10 & $0.097 \pm 0.00624$ \\
20 & $0.153 \pm 0.00415$ \\
& 40 & $0.186 \pm 0.00323$ \\
& 80 & $0.232+0.0008$ \\
& 100 & $0.278 \pm 0.00021$ \\
& 125 & $0.325 \pm 0.00343$ \\
Gallic acid & 150 & $0.416 \pm 0.006$ \\
& 1 & $0.091 \pm 0.00138$ \\
& 2.5 & $0.224 \pm 0.00288$ \\
& 5 & $0.315 \pm 0.00260$ \\
\hline
\end{tabular}

Values are expressed as mean \pm SD. $n=3$. CLA: Conjugated linoleic acid,

SD: Standard deviation

Table 6: $p$ values after statistical analysis

\begin{tabular}{lll}
\hline S. No & Method & p value \\
\hline 1 & Reducing power method & $<0.01$ \\
2 & Phosphomolybdenum antioxidant assay & $<0.04$ \\
3 & DPPH radical scavenging assay & $<0.01$ \\
4 & Hydroxy radical scavenging assay & $<0.05$ \\
5 & Nitric oxide radical scavenging assay & $<0.01$ \\
\hline
\end{tabular}

DPPH: 1,1-diphenyl-2-picrylhydrazyl

nitroprusside is known to decompose in aqueous solution at physiological $\mathrm{pH}$ (7.2) producing NO. Under aerobic conditions, NO reacts with oxygen to produce stable products (nitrate and nitrite), the quantities of which can be determined using Griess reagent [18]. $2 \mathrm{ml}$ of $10 \mathrm{mM}$ sodium nitroprusside dissolved in $0.5 \mathrm{ml}$ phosphate buffer saline (pH 7.4) is mixed with $0.5 \mathrm{~mL}$ of Griess reagent $(1.0 \mathrm{ml}$ sulfanilic acid reagent $0.33 \%$ in $20 \%$ glacial acetic acid at room temperature for $5 \mathrm{~min}$ with $1 \mathrm{ml}$ of naphthylethylenediamine dichloride $[0.1 \% \mathrm{w} / \mathrm{v}])$. The mixture is then incubated at room temperature for $30 \mathrm{~min}$ and its absorbance pouring into a curette is measured at $546 \mathrm{~nm}$. The amount of nitric oxide radical inhibition is calculated by the formula:

Scavenging activity of nitric oxide $=\left\{\left(A_{0}-A_{1}\right) / A_{0}\right\} \times 100$

Where, $A_{0}$ is absorbance of the control reaction (containing all reagents except sample extract),

and $\mathrm{A}_{1}=$ Absorbance of the sample extract.

Ascorbic acid was used as positive controls.

This test showed good free radical scavenging activity of CLA.

\section{RESULTS}

All experimental outcomes are presented as standard error of the mean \pm mean values. The data were analyzed using one-way analysis 
of variance; differences among samples were tested using Bonferroni's multiple comparison tests using SPSS version 20. All figures were plotted using SigmaPlot (version 8.0). Karl Pearson's correlation analysis $\left(\mathrm{r}^{2}\right)$ for correlation was performed between antioxidant activity and quantitative measurements using SPSS. $\mathrm{p}<0.05$ was considered statistically significant. In all the methods, $\mathrm{p}$ value is statistically significant.

The concentrations selected in these methods are $5,10,20,40,80,100$, 125 , and $150 \mu \mathrm{g} / \mathrm{ml}$. The higher absorbance was observed at $150 \mu \mathrm{g} / \mathrm{ml}$ in the reducing power method was 0.416 and in phosphomolybdenum method was 0.490. Table 1 shows the effects of CLA on hydroxy radical scavenging assay. Table 2 shows the effects of CLA on DPPH radical scavenging assay. Table 3 shows the effects of CLA on nitric oxide radical scavenging assay. Table 4 shows the effects of CLA on phosphomolybdenum assay. Table 5 shows the effect of CLA on reducing power method. Table 6 shows the $p$ values after statistical analysis.

\section{DISCUSSION}

The results obtained from this study clearly indicate that the CLA possesses antioxidant activity. CLAs were investigated for free radical scavenging properties against five methods for in vitro antioxidant activity. They are (1) reducing power method, (2) phosphomolybdenum method, (3) DPPH radical scavenging assay, (4) hydroxyl radical scavenging assay, and (5) nitric oxide scavenging assay.

In a study conducted by Lee et al. [19] to assess the effect of CLA on atherosclerosis, 12 rabbits were fed a semi-synthetic diet containing $14 \%$ fat and $0.1 \%$ cholesterol for 22 weeks. For six of these rabbits, the diet was augmented with CLA (0.5 g CLA/rabbit per day). Blood samples were taken monthly for lipid analysis. By 12 weeks, total and lowdensity lipoprotein (LDL) cholesterol and triglycerides were markedly lower in the CLA-fed group. Interestingly, the LDL cholesterol-to-highdensity lipoprotein (HDL) cholesterol ratio and total cholesterol-toHDL cholesterol ratio were significantly reduced in CLA-fed rabbits. Examination of the aortas of CLA-fed rabbits showed less atherosclerosis.

Spectrophotometric analysis showed the radical scavenging capacity of CLA in methanol and CLA can provide immediate protection against free radicals. This was proved in a study conducted by Yu [20]. CLAs were investigated for the free radical scavenging properties against the stable DPPH by electron spin resonance (ESR) spectrometry and spectrophotometric methods. ESR results demonstrated that CLA quenched free radicals and spectrophotometry results showed the radical scavenging capacity of CLA in ethanol. The results showed that CLA can provide immediate protection against free radicals.

In a study conducted by Sharma et al., antioxidative, anti-inflammatory, and antiatherosclerotic effect of taurine on hypercholesterolemia induced atherosclerotic rats was evaluated. Oral administration of taurine to rats showed antioxidantand anti-inflammatory activity by modulating oxidants in favor of reducing oxidative stress and also showed antiatherosclerotic activity in hypercholesterolemia-induced atherosclerosis [21].

From another study conducted by Leung and Liu et al. [22], it was found that $\mathrm{c} 9 \mathrm{t} 11$ isomer acted as a strong prooxidant and t10c12 CLA has got antioxidant properties. It was tested by total oxyradical scavenging capacity assay. At all concentrations, $(2-200 \mu \mathrm{M}) \mathrm{t} 10 \mathrm{c} 12$ CLA performed as an antioxidant with a $15 \mathrm{~min}$ lag phase and is more effective than c9t11 CLA and alpha-tocopherol at low concentrations. c9t11 CLA possessed weak antioxidant activity at $2-20 \mu \mathrm{M}$ and acted as a strong pro-oxidant at $200 \mu \mathrm{M}$.

Over the past 10 years, beneficial effects of dietary CLA have been focused on body composition, lipoprotein metabolism, carcinogenesis, cardiovascular disease, immune system, and diabetes $[23,24]$.

In a comparative study conducted by Melanathuru et al., the antioxidant and anticancer activity of Alpinia calcarata and Alpinia galanga were compared using the standard methods for in vitro antioxidant activity such as DPPH radical scavenging activity method, nitric oxide radical scavenging assay, and phosphomolybdenum assay [25].

In the continuation of the strategy of the new drug discovery, the authors studied the phytochemical composition, antioxidant, and antimicrobial properties of the methanolic leaf extract of A. indica plant [26]. In a similar way, in another study conducted by Premkumar et al., [27], the antioxidant activity of Acalypha indica crude leaf extract was tested by DPPH and other methods.

\section{CONCLUSION}

The CLA demonstrates free radical scavenging activity. As the concentration of the drug increased, the radical scavenging activity is also increased. In all methods, the CLA has shown the good antioxidant results. Among the antioxidant methods, the DPPH method has shown the best antioxidant result (84.55\%).

\section{ACKNOWLEDGMENTS}

The authors express their thanks to Principal of Aditya College of Pharmacy, Surampalem, Dr. Ravi Shankar Ph. D. for helping them to conduct the in vitro tests in his college for antioxidant activity of CLA.

\section{AUTHOR'S CONTRIBUTION}

All the authors have equally contributed to the article.

\section{CONFLICTS OF INTEREST}

The authors declare that they have no conflicts of interest.

\section{FUNDING SOURCE}

The project is self-funded.

\section{REFERENCES}

1. Ip C, Chin SF, Scimeca JA, Pariza MW. Mammary cancer prevention by conjugated dienoic derivative of linoleic acid. Cancer Res 1991;51:6118-24.

2. Kinnula VL, Crapo JD. Superoxide dismutases in malignant cells and human tumors. Free Radic Biol Med 2004;36:718-44.

3. Singh U, Jialal I. Oxidative stress and atherosclerosis. Pathophysiology 2006;13:129-42.

4. Sas K, Robotka H, Toldi J, Vécsei L. Mitochondria, metabolic disturbances, oxidative stress and the Kynurenine system, with focus on neurodegenerative disorders. J Neurol Sci 2007;257:221-39.

5. Bolton JL, Trush MA, Penning TM, Dryhurst G, Monks TJ. Role of quinones in toxicology. Chem Res Toxicol 2000;13:135-60.

6. Upston JM, Kritharides L, Stocker R. The role of vitamin E in atherosclerosis. Prog Lipid Res 2003;42:405-22.

7. Du M, Ahn DU, Nam KC, Sell JL. Volatile profiles andlipid oxidation of irradiated raw chicken meat patties from layinghens fed with diets containing conjugated linoleic acid. Meat Sci 2000;56:387-95.

8. Ha YL, Storkson J, Pariza MW. Inhibition of benzo(a)pyrene-induced mouse forestomach neoplasia by conjugated dienoic derivatives of linoleic acid. Cancer Res 1990;50:1097-101.

9. Hur SJ, Ye BW, Lee JL, Ha YL, Park GB, Joo ST, et al. Effects of conjugated linoleic acid on color and lipid oxidation of beef patties during cold storage. Meat Sci 2004;66:771-5.

10. Joo ST, Lee JI, Ha YL, Park GB. Effects of dietary conjugated linoleic acid on fatty acid composition, lipid oxidation, color, and water-holding capacity of pork loin. J Anim Sci 2002;80:108-12.

11. Badarinath AV, Rao KM, Chetty CM, Ramkanth V, Rajan TV, Gnanaprakash K. A review on in-vitro antioxidant methods: Comparisons, correlations and considerations. Int J Pharm Tech Res 2010;2:1276-85.

12. Jayaprakash GK, Singh RP, Sakariah KK. Antioxidant activity of grape seed extracts on peroxidation models in-vitro. J Agric Food Chem 2001;55:1018-22.

13. Prieto P, Pineda M, Aguilar M. Spectrophotometric quantitation of antioxidant capacity through the formation of a phosphomolybdenum complex: Specific application to the determination of vitamin E. Anal 
Biochem 1999;269:337-41.

14. Manzocco L, Anese M, Nicoli MC. Antioxidant properties of tea extracts as affected by processing. Lebenson Wiss Technol 1998;31:694-98.

15. Kunchandy E, Rao MA. Oxygen radical scavenging activity of curcumin. Int J Pharm 1990;58:237-40.

16. Bredt DS. Endogenous nitric oxide synthesis: Biological functions and pathophysiology. Free Radic Res 1999;31:577-96.

17. Marletta MAS. Nitric oxide: Biosynthesis and biological significance. Trends Biochem Sci 1989;14: 488-92.

18. Marcocci L, Maguire JJ, Droy-Lefaix MT, Packer L. The nitric oxidescavenging properties of ginkgo biloba extract EGb 761. Biochem Biophys Res Commun 1994;201:748-55.

19. Lee KN, Kritchevsky D, Pariza MW. Conjugated linoleic acid and atherosclerosis in rabbits. Atherosclerosis 1994;108:19-25.

20. Yu L. Free radical scavenging properties of conjugated linoleic acids. J Agri Food Chem.2001; 49:3452-6

21. Sharma H, Joshi A, Lad H, Bhatnagar D. Ansti-Oxidative, anti-inflammatory and anti-atherosclerotic effect of Taurine on hypercholesterolemia induced atherosclerotic rats. Int J Pharm Pharm Sci 2018;10:145-50.
22. Leung YH, Liu RH. Trans-10,cis-12-conjugated linoleic acid isomer exhibits stronger oxyradical scavenging capacity than cis-9,trans-11conjugated linoleic acid isomer. J Agric Food Chem 2000;48:5469-75.

23. Park Y, Albright KJ, Liu W, Storkson JM, Cook ME, Pariza MW, et al. Effect of conjugated linoleic acid on body composition in mice. Lipids 1997;32:853-8

24. West DB, Delany JP, Camet PM, Blohm F, Truett AA, Scimeca J, et al. Effects of conjugated linoleic acid on body fat and energy metabolism in the mouse. Am J Physiol 1998;275:R667-72.

25. Chajes V, Lavillonniere F, Maillard V, Giraudeau B, Jourdan ML, Sebedio JL, et al. Conjugated linoleic acid content in breast adipose tissue of breast cancer patients and the risk of metastasis. Nutr Cancer 2003;45:17-23.

26. Melanathuru V, Rengarajan S, Thangavel N. Comparative study of antioxidant and anticancer activity of Alpinia calcarata and Alpinia galanga. Int J Pharm Pharm Sci 2017;9:186-93.

27. Premkumar K, Nirmalababurao A, Rani R. Antimicrobial, antioxidant activity and phytochemical screening of Acalypha indica crude leaf extract. Int J Pharm Clin Res 2016;8:583-88. 